\title{
Fullers Earth Treatment for Esters Liquids used in Power Apparatuses: Inferences and Arguments
}

\author{
Issouf Fofana, Yohan Bergeron, Marie-Pier Gagnon, Jonathan Tremblay, Luc Loiselle, Kouba Marie Lucia Yapi, \\ and Ungarala Mohan Rao
}

\begin{abstract}
Insulating Liquids are widely used for their electrical and thermal properties in power apparatuses, particularly at the level of liquid-filled transformers. With the shift in engineering aspects towards sustainable development, it is important to find a sustainable solution with ecofriendly nature. Therefore, alternative (biodegradable) liquids are of high importance in the global transformer communities. In the present study, the alternative dielectric fluids (ester-based) feasibility for potential regeneration with Fuller's earth is investigated. The experimental results are confined to the reclamation temperature as well as the ratio of Fuller's earth (the sorbent) and the liquid. A suitable laboratory treatment apparatus is designed and is adopted in this study. Promising measurements to comment on the effectiveness of the treatment have been performed at controlled treatment temperature and sorbent-liquid ratio with the ASTM 7150-13 as a reference norm. The results of this study allowed $80^{\circ} \mathrm{C}$ and $1 \mathrm{~g} / 30 \mathrm{ml}$ as affirmative conditions for the present experimental conditions. Diagnostic measurements include turbidity, particle counter, and UV spectrophotometry before and after treatments. It is inferred that fuller's earth is not a promising sorbent for the reclamation of ester liquids.
\end{abstract}

Keywords-Transformer, Dielectric Liquid, Esters, Regeneration.

\section{INTRODUCTION}

The electric power grid has evolved greatly as technologies have refined with advancements in digital technologies and high-power demands. Power transformers connected across the grid allow the voltage levels of power lines to be raised and lowered, which saves a lot in terms of loss of electrical power, thus saving a lot of money [1]. However, the power transformer is one of the extremely expensive equipment connected over the grid. For this reason, companies, factories, and owners of electrical networks do not hesitate to spend many thousands of dollars on transformer maintenance and devices to protect its health integrity. Given that insulation systems in the transformers play a critical role in deciding the health index and service life of a transformer, high emphasis is laid on the transformer's insulation system [2]. In addition to protecting these important machines, the utility engineers need to have the condition of transformers assessed in order to prevent malfunction and avoid premature aging [3]. Different stresses including electrical, thermal, and chemical, accelerate the degradation of liquid and solid insulation in the transformers [4]. Different stress has a different effect on the nature of degradation, and this is attributable to the type of insulating material. Since the beginning of transformer technology,

\footnotetext{
Manuscript received May 4, 2021; revised May 28, 2021.

Issouf Fofana, Luc Loiselle, Ungarala Mohan Rao and Kouba Marie Lucia Yapi are with the Department of applied sciences, University of Quebec at Chicoutimi, CANADA.

(e-mail: $\quad$ ifofana@uqac.ca; luc.loiselle@uqac.ca; mohan.ungarala1@uqac.ca;KoubaMarieLucia1_Yapi@uqac.ca)

Yohan Bergeron, Marie-Pier Gagnon, and Jonathan Tremblay were with the Department of applied sciences, University of Quebec at Chicoutimi, CANADA. (e-mail: yohan.bergeron1@uqac.ca; marie-pier.gagnon3@uqac.ca; jonathan.tremblay14@uqac.ca)
}

Digital Object Identifier (DOI): 10.53907/enpesj.v1i1.33 mineral oils with solid cellulose insulations are widely accepted. However, mineral oils are facing critiques due to their toxicity, low flashpoints as well as limited dielectric properties. The details of the same are elaborated by major authors $[5,6]$.

Therefore, alternative and biodegradable liquids, both natural and synthetic esters, are reported affirmatively for possible use in liquid-filled transformers [6-9]. The service behavior [10], paper degradation $[11,12]$, pre-breakdown behavior [13], liquid degradation $[11,14,15]$ are reported affirmatively by various authors. In addition, the gassing tendency and influence of various faults on the gassing and definite liquid degradations have been widely reported by authors [16]. Various authors in different works mentioned above also reported the physiochemical behavior of the ester liquids. It is inferred that esters are hydrophilic at the outset and therefore exhibit a higher water saturation limit, improve hydrolysis rates and thus keep the cellulose insulation dry. This in turn improves the rate of degradation of cellulose in esters and reduces decay concentration in the liquids. Despite few limitations, phenomenal service and technical benefits outweigh these new liquids for high-voltage devices. However, there is a need to understand these new liquids' end-life behavior in order to rejuvenate, recycle or reuse phenomena. The reclamation aspects of mineral insulating liquids used in transformers and liquid-filled electrical apparatus is reported in the IEEE standard C57. 637 [2]. There is no established standard for the reclamation of ester liquids [2]. Nevertheless, various authors reported the regeneration of esters with various adsorbents. The details of the adsorbents are not well discussed in the existing literature. The factory dehydration and degassing process remain the same; the treatment temperature should be around $70^{\circ} \mathrm{C}$. High temperatures will influence the oxidation stability of the ester liquids and definitely have a notable impact on the weight of the available antioxidants in the bulk of the liquid [2]. To the best of the author's knowledge, this treatment temperature is not yet investigated by researchers or reported in the existing literature. Thus, this work aims to investigate the feasibility of fuller's earth for regeneration of esters before the 
new adsorbents or absorbents are investigated.

In the authors' recent work [17], the ability and influence of ester to generate the decay particles viz. soluble particles and colloidal particles have been investigated for sludge monitoring in these new liquids. It is found that esters generate less sludge or colloids and have high scope for the generation of soluble decay particles. However, it is an argument that ester dissolves sludge after a generation or does not generate any sludge with degradation. Therefore, in this work, the potential of the widely accepted sorbent for transformer oils that is Fuller's earth has been identified as the subject. A large number of papers have reported the reclaiming of damaged insulating mineral oils. The processes used were re-refining with chemicals [18] activated alumina or Fuller's earth [19].The performance of Fuller's earth has been verified under selected conditions adopted for the treatment of the ester liquids in comparison to mineral oils. The laboratory-aged liquids are filtered using Fuller's earth at different treatment temperatures and different sorbent-liquid ratios to understand the effectiveness of the treatment. It is inferred that Fuller's earth is not a potential sorbent for treating esters and the filtration at $80^{\circ} \mathrm{C}$ is better than the other pretreatment temperatures. Also, the $1 \mathrm{~g} / 30 \mathrm{ml}$ ratio is found to be effective for a single pass analysis. However, the effectiveness is claimed based on few important diagnostic measurements. Further, detailed analysis and more quantitative measurements need to be performed to open the door for research on alternative sorbents for ester liquids.

\section{EXPERIMENTAL}

The present investigation is performed on three different insulating liquids with an aim to understand the potential of fuller's earth for possible regeneration of aged ester liquids. However, the emphasis is laid on the pretreatment temperature and ratio of the fuller's earth and liquid. Therefore, the conditions outlined in the ASTM D 7150 are considered as a reference for the present study. The insulating liquids are aged, and the diagnostic characteristics of these aged liquids are considered a benchmark for the treated liquids. Following the reclamation of the aged liquids at different aging factors, the diagnostic characteristics are compared at different reclamation conditions.

\section{A. Materials and Apparatus}

The insulating liquid mineral oil (MO), natural ester (NE), and synthetic ester (SE) are aged as per ASTM D1934 under open beaker aging conditions in the presence of cellulose $(1: 20)$ and copper catalyst $(3 \mathrm{~g} / \mathrm{l})$. Thermal aging is performed at $115^{\circ} \mathrm{C}$ with an aging history at 500 hours, 1000 hours, and 1500 hours. These high-aging durations under open beaker conditions allowed the insulating materials to degrade to a greater extent and introduce the aging by-products into the liquids. As discussed earlier, treatment temperature and sorbent-liquid ratios are the prime focus for the present study. Thus, a laboratory-based setup is developed, which controls the treatment temperature and sorbent volume in the reclamation column. In order to have good temperature control, it is imperative to use a well-distributed heating system around our reclamation compartment. In this context, a heating element is wrapped around fuller's earth chamber to achieve the desired temperature where the liquid is reclaimed. The heating element is shown in Figure 1(a).This heating element is wrapped around the glass syringes in which a bed of cotton is placed and above this the Fuller's earth is hosted. Two parallel inlets for the liquid are planned to save reclamation time. The view of these reclamation tubes is shown in Figure 1(b). The complete view of the experimental along with the supply and temperature control unit is presented in Figure 1.

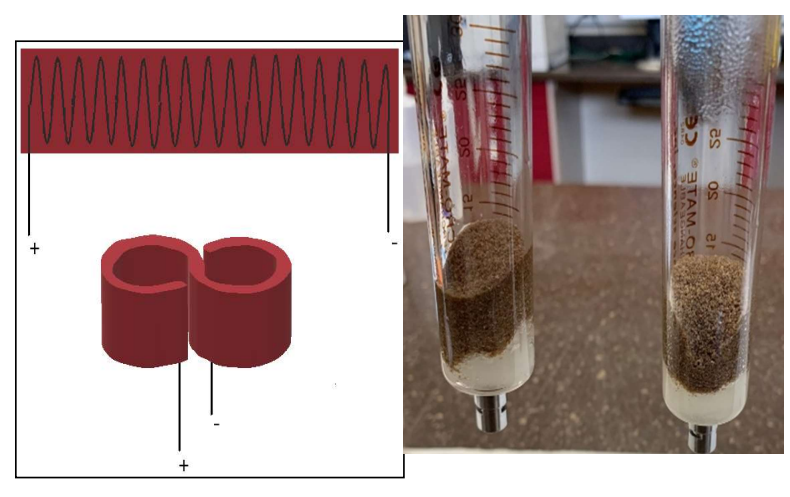

(a)

(b)

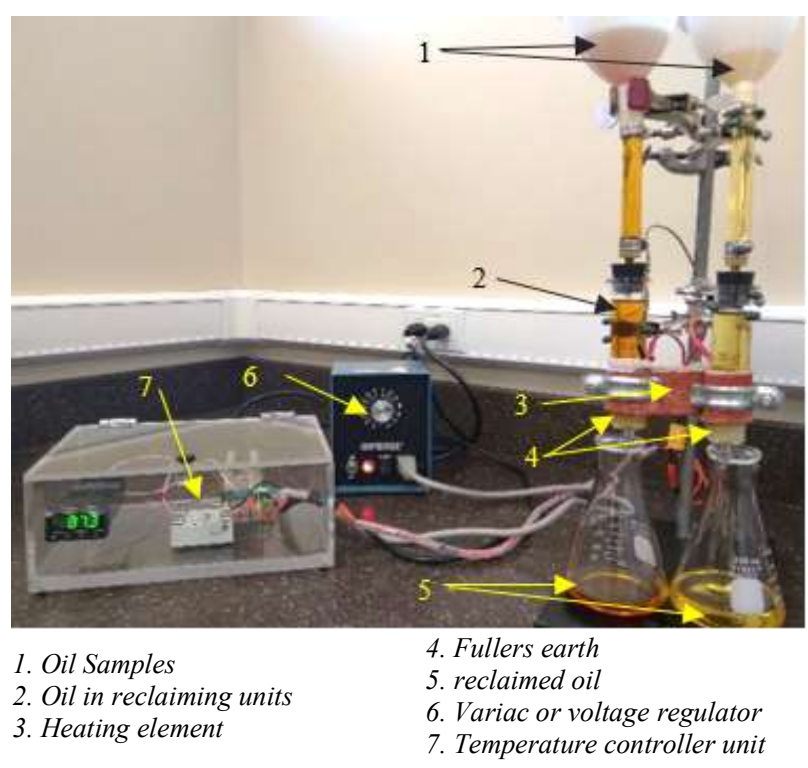

(c)

Fig. 1: View of the laboratory model for Fuller's earth reclamation.

\section{B. Measurements}

The aged liquids are tested for turbidity, UV spectroscopy, and particles counter to understand the level of degradation and degree of contamination of the liquids due to aging. Besides, the aged liquids are reclaimed at sorbent-liquid ratios of $1 \mathrm{~g} / 30 \mathrm{ml}, 1 \mathrm{~g} / 35 \mathrm{ml}$, and $1 \mathrm{~g} / 40 \mathrm{ml}$ to have control of the ratio. All the three ratios are tested at a treatment temperature of $70^{\circ} \mathrm{C}, 80^{\circ} \mathrm{C}$, and $90^{\circ} \mathrm{C}$ to understand the influence of treatment temperature. The insulating liquids are heated to the set treatment temperature before passing through the heated reclaiming tubes which are maintained at the desired treatment temperature. This ensures that the reclamation is performed when the liquid and the fuller's earth are both held at the same treatment temperature. The reclaimed fluid is collected and tested for turbidity, UV spectroscopy, and particles counter to understand the level of reclamation. The results and discussion section will focus on the comparative discussion of the results to understand the influence of temperature and sorbent ratio at different aging conditions. 


\section{RESULTS AND DISCUSSION}

\section{A. Influence of Treatment Temperature}

The treatment temperature is a vital parameter for the insulating liquid regeneration process. It is a major parameter that could decide the efficiency of the sorbent and the effectiveness of the treatment process. The sorption process, either adsorption or absorption that undergoes during the treatment, is attributable to the sorbent's surface properties. The surface properties of any sorbent are temperature-dependent and vary based on the nature of the decay products in the feed liquid. In particular, the sorption efficiency is high when the process is carried while the sorbent is activated. Thus highlighting, the temperature called activation temperature for the sorbent. However, this activation temperature should be in agreement with the oxidation stability of the feed liquid. Therefore, a careful evaluation of pretreatment temperatures is required for new insulating liquids and sorbents. In this section, the change in turbidity and dissolved decay products of the liquids at different aging factors treated at different treatment temperatures have been discussed.

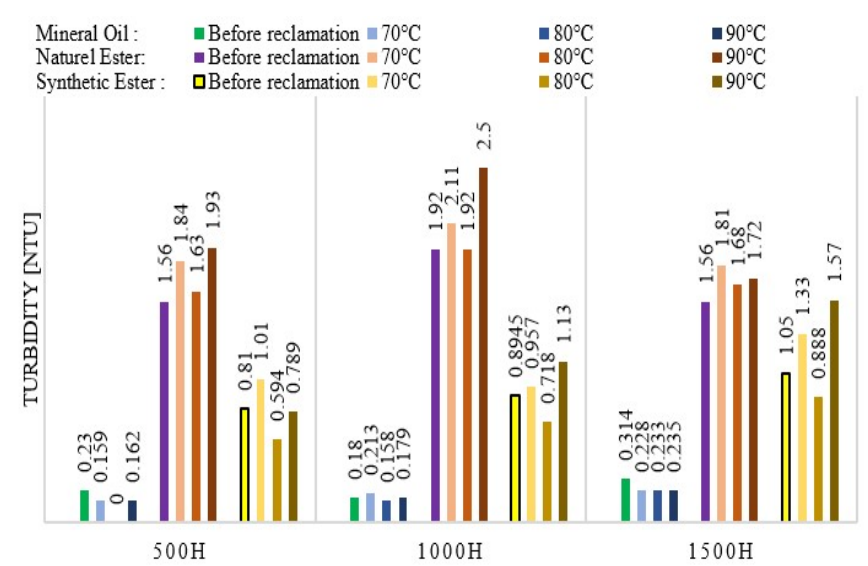

(a) Change in the turbidity of various liquids reclaimed at $1 \mathrm{~g} / 35 \mathrm{ml}$

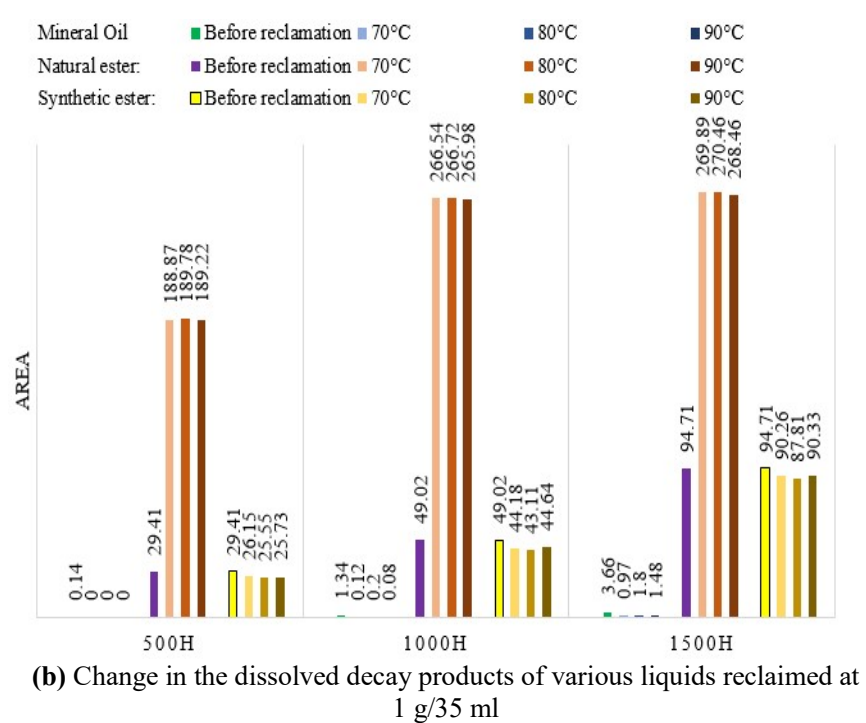

Fig. 2. Changes in the liquid properties before and after reclamation at different temperatures.

The change in turbidity of the liquids measured after reclamation at $70^{\circ} \mathrm{C}, 80^{\circ} \mathrm{C}$, and $90^{\circ} \mathrm{C}$ are presented in Figure 2(a). It is seen that the turbidity values increase with normal aging. However, the turbidity is not noticed to be reduced with reclamation in liquids, especially for the ester-based liquids. It is noticed that the increase of turbidity is slightly less at $80^{\circ} \mathrm{C}$ of treatment temperature as compared to $70^{\circ} \mathrm{C}$ and $90^{\circ} \mathrm{C}$. The dissolved decay contents are also noticed not to have any significant change with the fuller's earth reclamation in case of ester liquids. Also, the selected range of treatment temperatures have the least influence on the reclamation of ester liquids. However, the reclamation of esters with Fuller's earth is found unsatisfactory for the present experimental conditions.

\section{B. Influence of Liquid-Sorbent Ratio}

Similar to treatment temperature, the sorption ratio also has a significant influence on the treatment process. This is because the sorption process, either absorption or adsorption (starts with absorption phenomena) is controlled by the surface properties of the sorbent, as discussed in the previous sections. At this level, it is important to add the property called sorption saturation. This indicates that the sorbent loses its ability to absorb or adsorb any further particles from the feed after this saturation limit. Thus, an optimal sorbent-liquid ratio is essential to be obeyed for the reclamation of different liquids. Unfortunately, there is no published data on the knowledge of these ratios in the case of ester liquids. In other words, a sorbent will have different saturation limits with different insulating liquids. The reclamation or sorption process is efficient when the reclamation is performed below the sorption saturation limit. To comment on the ratios, liquids at different aging conditions have been reclaimed at different Fuller's earth-liquid ratios. The change in turbidity and dissolved decay products with reclamation at different ratios performed at $80^{\circ} \mathrm{C}$ are shown in Figure 3.

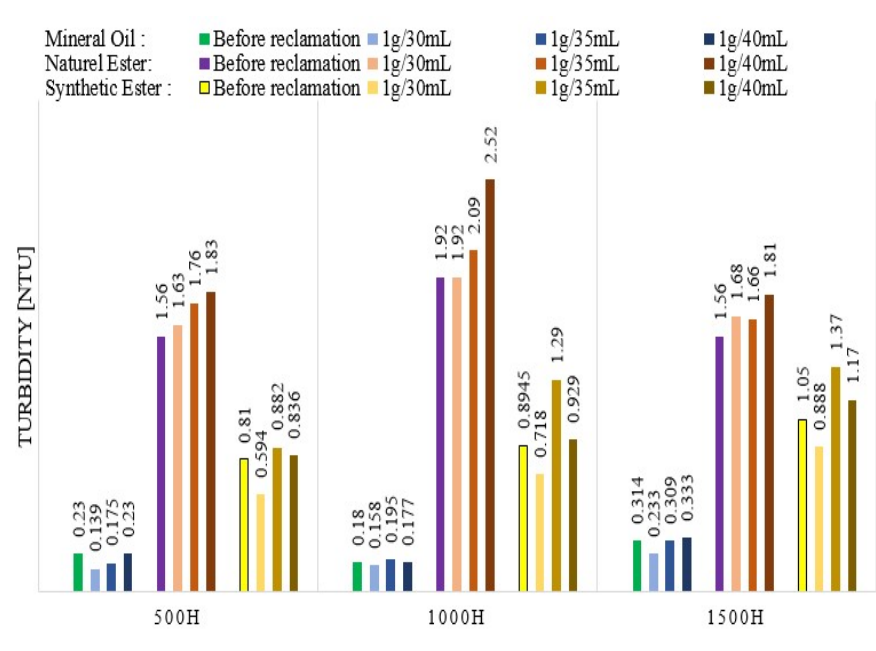

(a) Change in turbidity of various liquids reclaimed at $80^{\circ} \mathrm{C}$

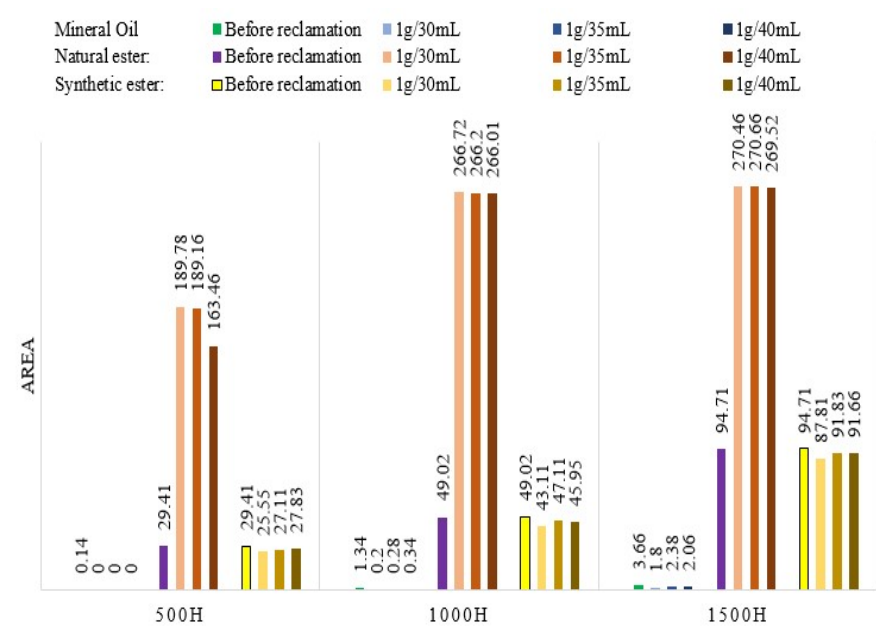

(b) Change in dissolved decay products of various liquids reclaimed at $80^{\circ} \mathrm{C}$

Fig. 3. Changes in the liquid properties before and after reclamation at different sorption-liquid ratios.

The change in turbidity with different sorbent-liquid ratios has been presented in Figure 3(a). It is observed that turbidity is 
increasing with an increase in the feed liquid volume in the case of natural esters, and is randomly changing in the case of synthetic esters. However, $1 \mathrm{~g} / 30 \mathrm{ml}$ is found to be better in the present range of ratios in the case of synthetic esters. The change in dissolved decay products has been presented in Figure 3(b) for liquids reclaimed at different ratios were no significant changes are noticed with a change in the sorbentliquid ratio. To further understand, the same particle count measurements are performed on all the liquids reclaimed at different ratios and are presented in Figure 4 for mineral oils, synthetic esters, and natural esters.

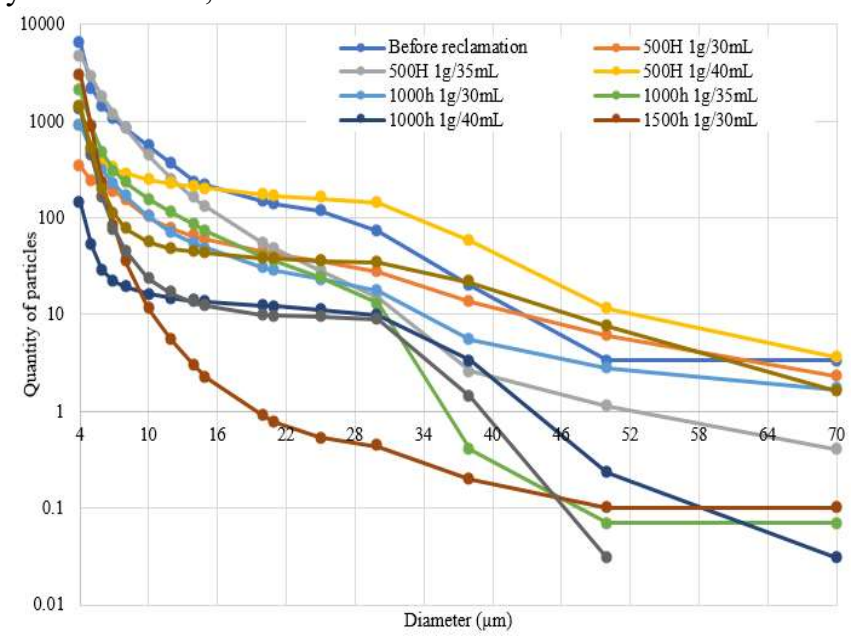

(a) Change in particle count of mineral oils reclaimed at $80^{\circ} \mathrm{C}$

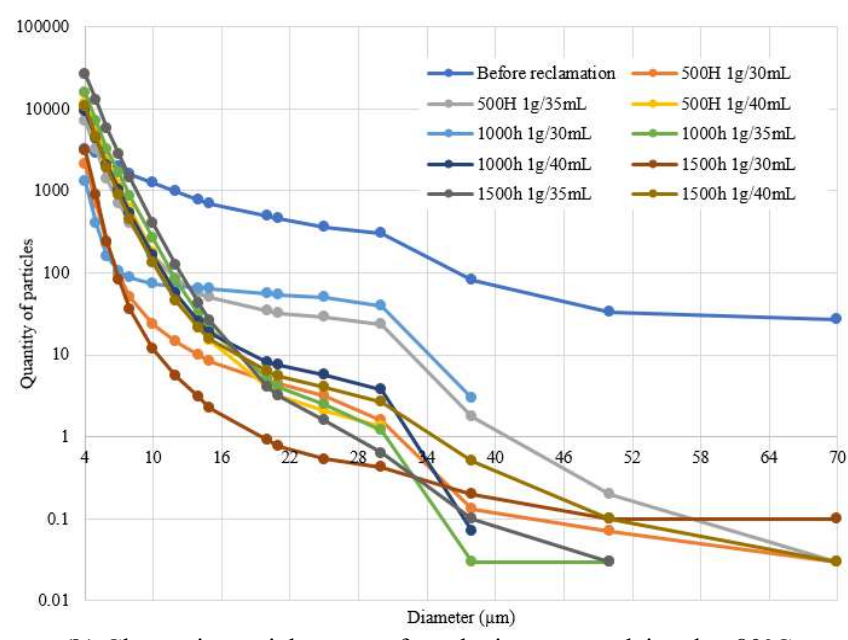

(b) Change in particle count of synthetic esters reclaimed at $80^{\circ} \mathrm{C}$

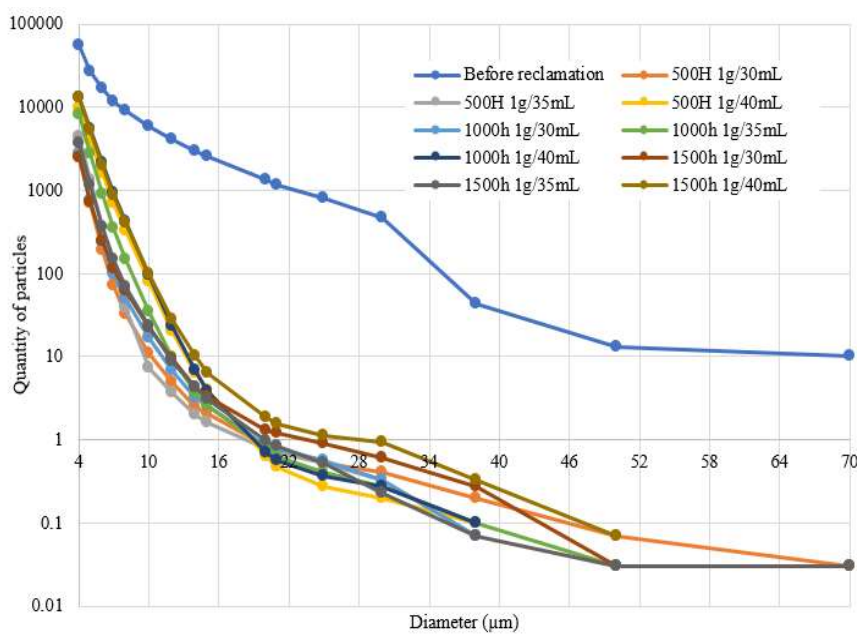

(c) Change in particle count of natural esters reclaimed at $80^{\circ} \mathrm{C}$

Fig. 4. Changes in the particle count in the liquids before and after reclamation at different sorption-liquid ratios.
The change in total particles in mineral oil, synthetic esters, and natural esters with reclamation has been reduced. However, a reduction of higher diameter particles is noted with reclamation. This may be assumed that the decay particles having higher diameters have been reclaimed out. However, the increase in the smaller diameter particles with reclamation is questionable and needs further investigations.

\section{IV.CONCLUSION}

In this work, mineral oil, synthetic ester, and natural ester reclamation have been performed using Fuller's earth at different temperatures and sorbent-liquid ratios. The aged liquids have been characterized for turbidity, UV spectroscopy (dissolved decay products), and particle count. Based on the present measurements, the reclamation performed at $1 \mathrm{~g} / 30 \mathrm{ml}$ as well as heated to a temperature of $80^{\circ} \mathrm{C}$ is a compromising option. While Fuller's Earth is used worldwide for mineral reclamation, its application to ester liquids is questionable. There is a need to further analyze viscosity, acidity, FTIR, and density changes with filtration. In addition, the flow rate, the shape of the reclamation column (that is, a very narrow, less narrow, and a wide syringe), and the number of reclamation cycles are also influential factors of major importance.

\section{REFERENCES}

[1] G. C. Montanari, R. Hebner, P. Morshuis, and P. Seri, "An Approach to Insulation Condition Monitoring and Life Assessment in Emerging Electrical Environments," IEEE Transactions on Power Delivery, vol. 34, no. 4, pp. 1357-1364, 2019, doi: 10.1109/tpwrd.2019.2897905.

[2] U. Mohan Rao, I. Fofana, and J. S. N'Cho, "On Some Imperative IEEE Standards for Usage of Natural Ester Liquids in Transformers," IEEE Access, vol. 8, pp. 145446-145456, 2020, doi: 10.1109/access.2020.3014600.

[3] V. M. Catterson et al., "The impact of smart grid technology on dielectrics and electrical insulation," IEEE Transactions on Dielectrics and Electrical Insulation, vol. 22, no. 6, pp. 3505-3512, 2015, doi: 10.1109/tdei.2015.00518.

[4] I. Fofana, A. Bouaicha, M. Farzaneh and J. Sabau, "Ageing Behaviour of Mineral Oil and Ester Liquids: a Comparative Study," 2008 Annual Report Conference on Electrical Insulation and Dielectric Phenomena, 2008, pp. 87-90.

[5] I. Fofana, "50 years in the development of insulating liquids," IEEE Electrical Insulation Magazine, vol. 29, no. 5, pp. 15-25, 2013.

[6] U. Mohan Rao, I. Fofana, T. Jaya, E. M. Rodriguez-Celis, J. Jalbert, and P. Picher, "Alternative Dielectric Fluids for Transformer Insulation System: Progress, Challenges, and Future Prospects," IEEE Access, vol. 7, pp. 184552-184571, 2019, doi: 10.1109/access.2019.2960020.

[7] M. Rafiq et al., "Use of vegetable oils as transformer oils - a review," Renewable and Sustainable Energy Reviews, vol. 52, pp. 308-324, 2015, doi: 10.1016/j.rser.2015.07.032.

[8] D. M. Mehta, P. Kundu, A. Chowdhury, V. K. Lakhiani, and A. S. Jhala, "A review on critical evaluation of natural ester vis-a-vis mineral oil insulating liquid for use in transformers: Part 1," IEEE Transactions on Dielectrics and Electrical Insulation, vol. 23, no. 2, pp. 873-880, 2016, doi: 10.1109/tdei.2015.005370.

[9] D. M. Mehta, P. Kundu, A. Chowdhury, V. K. Lakhiani, and A. S. Jhala, "A review of critical evaluation of natural ester vis-a-vis mineral oil insulating liquid for use in transformers: Part II," IEEE Transactions on Dielectrics and Electrical Insulation, vol. 23, no. 3, pp. 1705-1712, 2016, doi: 10.1109/tdei.2016.005371

[10] D. Martin, T. Saha, and L. McPherson, "Condition monitoring of vegetable oil insulation in in-service power transformers: some data spanning 10 years," IEEE Electrical Insulation Magazine, vol. 33, no. 2, pp. 44-51, 2017.

[11] I. Fernández et al., "Thermal degradation assessment of Kraft paper in power transformers insulated with natural esters," Applied Thermal Engineering, vol. 104, pp. 129-138, 2016, doi: 10.1016/j.applthermaleng.2016.05.020.

[12] U. Mohan Rao and R. K. Jarial, "Measurement of transformer solid insulation degradation using dilatometry and X-ray diffraction analysis," Measurement, vol. 131, pp. 701-705, 2019, doi: 10.1016/j.measurement.2018.09.024.

[13] U. Mohan Rao et al., "A review on pre-breakdown phenomena in ester fluids: Prepared by the international study group of IEEE DEIS liquid 
dielectrics technical committee," IEEE Transactions on Dielectrics and Electrical Insulation, vol. 27, no. 5, pp. 1546-1560, 2020, doi: 10.1109/tdei.2020.008765.

[14] U. Mohan Rao, Y. N. Kumar, and R. K. Jarial, "Understanding the ageing behaviour of transformer oil-paper insulation with ester and mixed dielectric fluids," IET Science, Measurement \& Technology, vol. 12, no. 7, pp. 851-857, 2018, doi: 10.1049/iet-smt.2018.0110.

[15] I. Fernández, A. Ortiz, F. Delgado, C. Renedo, and S. Pérez, "Comparative evaluation of alternative fluids for power transformers," Electric Power Systems Research, vol. 98, pp. 58-69, 2013, doi: 10.1016/j.epsr.2013.01.007.

[16] L. Loiselle, U. Mohan Rao, and I. Fofana, "Gassing Tendency of Fresh and Aged Mineral Oil and Ester Fluids under Electrical and Thermal Fault Conditions," Energies, vol. 13, no. 13, 2020, doi: 10.3390/en13133472

[17] L. Loiselle, U. Mohan Rao, I. Fofana, and T. Jaya, "Monitoring colloidal and dissolved decay particles in ester dielectric fluids," IEEE Transactions on Dielectrics and Electrical Insulation, vol. 27, no. 5, pp. 1516-1524, 2020. doi: 10.1109/TDEI.2020.008719

[18] W.G. Barlow, "Reclaiming of Transil Oil by a Sulphuric Acid Process". Minutes of the Eleventh Annual International Conference of Doble Clients Boston. sec. 10-201, 1944.

[19] J. S. N'cho, I. Fofana, A. Beroual, T. Aka-Ngnui and J. Sabau, 'Aged oils reclamation: Facts and arguments based on laboratory studies"'. IEEE Transactions on Dielectrics and Electrical Insulation, vol. 19, 1583-1592, 2012. doi: 10.1109/TDEI.2012.6311504

Issouf Fofana obtained his electro-mechanical engineering degree in 1991 from the University of Abidjan (Côte d'Ivoire), and his master's and doctoral degrees from École Centrale de Lyon, France, in 1993 and 1996, respectively. He was a postdoctoral researcher in Lyon in 1997 and was at the Schering Institute of High Voltage Engineering Techniques at the University of Hanover, Germany from 1998 to 2000 . He was a Fellow of the Alexander von Humboldt Stiftung from November 1997 to August 1999. He joined University of Quebec at Chicoutimi (UQAC), Quebec, Canada as an Associate Researcher in 2000, and he is now a professor there. Dr. Fofana has held the Canada Research Chair, tier 2, of insulating liquids and mixed dielectrics for electrotechnology (ISOLIME) from 2005 to 2015. Actually, he is leading the Research Chair on the Aging of Power Network Infrastructure (ViAHT). He is also director of the MODELE laboratory and the International Research Centre on Atmospheric Icing and Power Network Engineering (CenGivre) at UQAC. He is the chair of the IEEE DEIS Technical committee on Dielectric Liquids. He has authored/co-authored over 300 scientific publications, three book chapters, one textbook, edited three books and holds three patents. Dr Fofana is an IEEE Senior Member and IET Fellow.

Yohan Bergeron graduated in 2019 at the University of Quebec at Chicoutimi (UQAC), Quebec, Canada. So far, he is working with WSP Canada Saguenay, Québec, Canada as consultant. His main interests include renewable energy, energy management and power systems analysis.

Marie-Pier Gagnon graduated in 2019 at the University of Quebec at Chicoutimi (UQAC), Quebec, Canada. So far, he is working with Voltam Inc. Saguenay, Québec as professional engineer. Her main interests include power systems analysis and protection.

Jonathan Tremblay was a graduate student in the department of applied sciences at the University of Quebec at Chicoutimi (UQAC), Canada. During his finishing school project, he worked with the Research Chair on the Aging of Power Network Infrastructure (ViAHT) for four months.

Luc Loiselle received his Bachelor's degree in Electrical Engineering in 2006, his Master's degree in 2013 and his $\mathrm{PhD}$ in 2021 from the University of Quebec at Chicoutimi (UQAC), Canada. He is registered professional engineer in the province of Quebec (Ordre des Ingénieurs du Québec, Canada. From 2006-2016, he was a consultant in engineering at Centre des Services aux Enterprises (Saguenay, Canada). Since 2018, he is working as electrical engineer with Tetra Tech, Saguenay (Canada). His main research interests include high-voltage, electrical insulation, dielectric materials and safety. He has coauthored/authored dozen of scientific publications.

Kouba Marie Lucia Yapi graduated in Engineering in 2012 from the University of Quebec at Chicoutimi (UQAC), Canada. Since 2013, she is working as research professional at the UQAC (from 2013-2015: with the Canada Research Chair on insulating liquids and mixed dielectrics for electrotechnology: ISOLIME, and since 2013 with the Research Chair on the Aging of Power Network Infrastructure: ViAHT, UQAC). She is registered professional junior engineer in the province of Quebec (Ordre des Ingénieurs du Québec, Canada). Her main research interests focus on power transformer diagnostics.

Ungarala Mohan Rao obtained his bachelor's degree in electrical and electronics engineering from Jawaharlal Nehru Technological University, Kakinada, India in 2010. He obtained his master's and doctoral degrees from the National Institute of Technology (NIT), Hamirpur, India, in 2012 and 2017 respectively. At present, he is a lecturer in the Department of Applied Sciences (DSA) at University of Quebec at Chicoutimi (UQAC), Québec, Canada. Since 2018, he is also a postdoctoral researcher at UQAC with the Research Chair on the Aging of Power Network Infrastructure (ViAHT). Dr. Mohan is a Senior Member of IEEE and Member of the IEEE DEIS. He is also the Secretary for the IEEE Technical Committee on "Liquid Dielectrics". His main research interests include aging phenomena of high-voltage insulation, condition monitoring of electrical apparatus, alternative dielectric materials, transformer insulation in cold countries, and AIML applications. 